\title{
Development of Eucalyptus tissue culture conditions for improved in vitro plant health and transformability
}

\author{
Cathleen Ma', Raj Deepika², Alexander A Myburg², Martin Ranik', Steven H Strauss ${ }^{1 *}$ \\ From IUFRO Tree Biotechnology Conference 2011: From Genomes to Integration and Delivery \\ Arraial d Ajuda, Bahia, Brazil. 26 June - 2 July 2011
}

\section{Background}

Despite its importance as a widely-planted crop tree, eucalypt species and hybrids are relatively difficult to micropropagate, culture and genetically transform in vitro. Compared to other plant species, few non-commercial laboratories are proficient at Eucalyptus tissue culture and transformation. We have undertaken to establish and transform several eucalypt clones in the laboratory. Our main aims include the identification of clones amenable to culturing and transformation, and the development of robust and transferable micropropagation, organogenesis and transformation protocols to enable routine production of transgenic eucalypts for public sector research. Efficient transformation protocols are essential to take full value of the eucalypt genome for functional genomics, ecophysiology, and biotechnology.

\section{Methods}

Five different clones of $E$. grandis (including the clone of which the genome was recently sequenced - Brasuz1) as well as a single E. grandis x urophylla hybrid were established in the laboratory. Light intensity was studied as a means to reduce browning and promote callus growth and shoot regeneration. Gibberelic acid $\left(\mathrm{GA}_{3}\right)$ concentrations in the micropropagation medium (Murashige and Skoog's (MS) basal medium containing $0.05 \mathrm{mg} / \mathrm{L}$ benzylaminopurine - BAP) were studied to help produce long internodes to aid transformation in vitro. To mitigate phenolic production we used several different antioxidants including ascorbic acid, PVP and PVPP. Shoot regeneration rates were studied by testing a concentration range of cytokinin

\footnotetext{
* Correspondence: Steve.Strauss@oregonstate.edu

'Department of Forest Ecosystems and Society, 321 Richardson Hall, Oregon State University, Corvallis, OR, 97331-5752, USA

Full list of author information is available at the end of the article
}

(zeatin, benzyl aminopurine - BAP and thidiazuron TDZ). We tested different Agrobacterium transformation protocol enhancements including the use of acetorsyringone and two different co-cultivation techniques (whole explant immersion versus pipetting of Agrobacterium suspension onto cut leaf edges). We also tested the suitability of kanamycin and hygromycin as selectable markers during transformation.

\section{Results and discussion}

Light conditions during shoot regeneration were critical to the rate of organ regeneration, with more than $50 \%$ of explants producing shoots in the presence of reduced or indirect light, compared to approximately $30 \%$ incubated under normal light conditions. In addition, shoot differentiation occurred earlier (10-14\% at 40 days) under reduced or indirect light compared to normal light (1\%; Fig. 1).

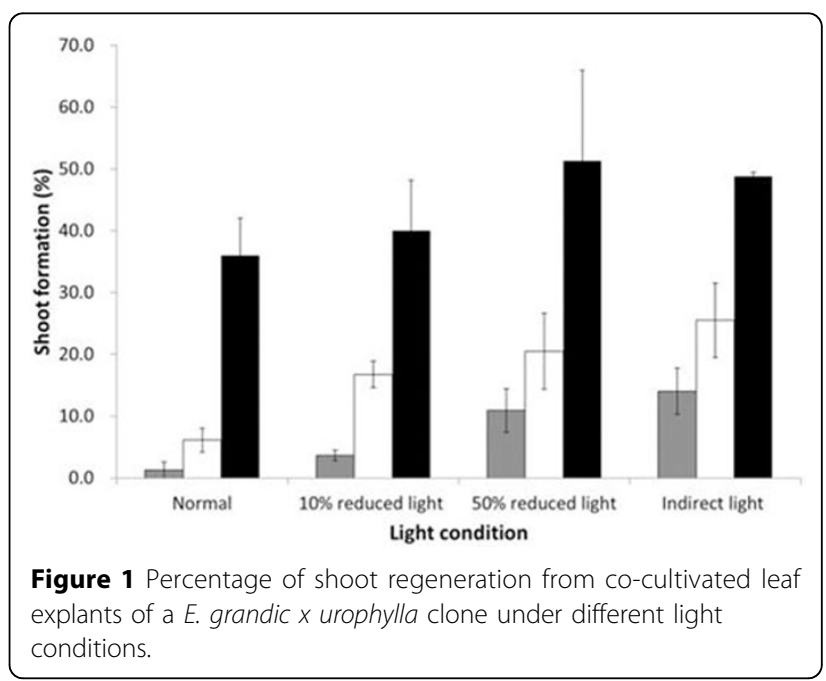

(C) 2011 Ma et al; licensee BioMed Central Ltd. This is an open access article distributed under the terms of the Creative Commons 
We have also begun to test the use of muslin screens to identify the best level of light exposure. The optimal level of $\mathrm{GA}_{3}$ in the micropropagation medium for the production of sturdy elongated internodes was found to be $0.05 \mathrm{mg} / \mathrm{L}$. It was also apparent that the recovery of micropropagated plantlets on medium without $\mathrm{GA}_{3}$ for 21 days prior to internode harvesting improved plant health and produced better quality stem sections for transformation. Ascorbic acid, used as a means of reduction of phenolic browning, proved to be ineffective when used alone, even though it produced no adverse effects on callus health. By comparing several shoot induction media (SIM) for shoot regeneration from stem and leaf explants of the E. grandis x urophylla
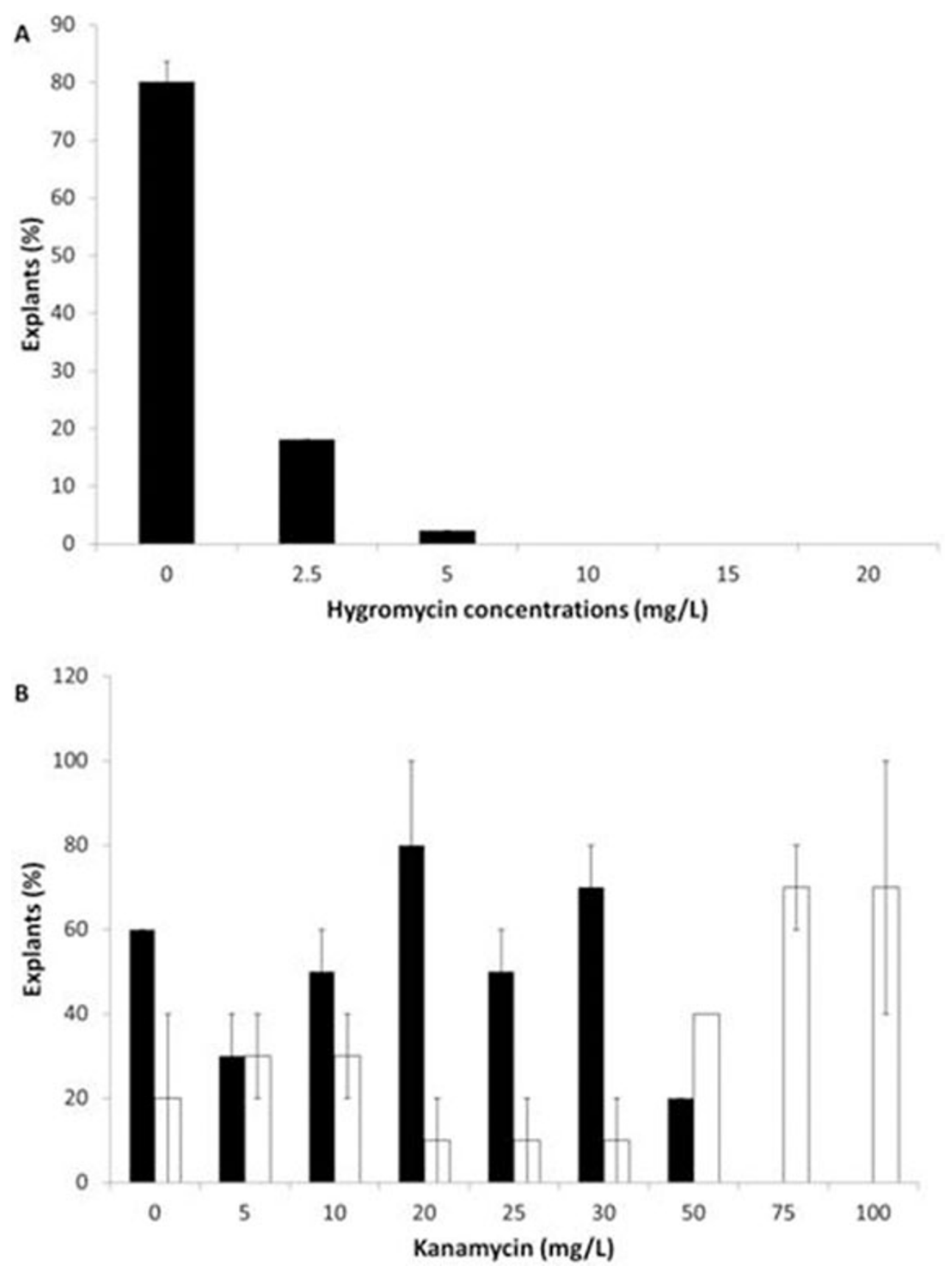

Figure 2 A. Percentage of non-transgenic explants forming callus after 30 days on shoot induction medium (SIM) with different concentrations of hygromycin. B. Percentage of explants forming roots (black bars) and exhibiting shoot yellowing (white bars). This experiment was conducted on a single kanamycin-resistant transgenic line of a E. grandis $x$ urophylla clone after 30 days on rooting medium. 
containing different cytokinin combinations, we found that the highest rates of shoot regeneration (11.8\%) occurred when using stem explants incubated on SIM containing $1 \mathrm{mg} / \mathrm{L}$ NAA (nicotinamide) and $10 \mathrm{mg} / \mathrm{L}$ zeatin. Of the five tested $E$. grandis clones, we found that the highest rates of shoot regeneration (52\%) were from leaf explants of clone p207 in the presence of SIM containing $3 \mu \mathrm{M} \mathrm{TDZ}$ and $0.1 \mu \mathrm{M}$ NAA. Neither the use of two different acetosyringone concentrations (250 and $750 \mu \mathrm{M})$ during co-cultivation, nor either of the two co-cultivation techniques (immersion and pipetting) had a significant effect on transient gene expression measured shortly after cocultivation. Testing of different kanamycin and hygromycin concentrations ("kill curve"), revealed that $30 \mathrm{mg} / \mathrm{L}$ kanamycin or $5 \mathrm{mg} / \mathrm{L}$ hygromycin can be used for the selection of putative transgenics after transformation (Fig. 2).

\section{Conclusions}

There is significant variability in the performance and response of different clones of Eucalyptus during micropropagation, organogenesis and transformation. Testing of multiple Eucalyptus clones confirmed that the genus is relatively unwieldy in tissue culture compared, for example, to Populus. We found that explant type (stem vs leaf for example), and quality (age, general health, absence callus browning) as well as finely-tuned phytohormone concentrations, will play critical roles in enhancing the probability of the successful generation of stable transgenic lines.

\section{Author details}

${ }^{1}$ Department of Forest Ecosystems and Society, 321 Richardson Hall, Oregon State University, Corvallis, OR, 97331-5752, USA. '2Department of Genetics, Forestry and Agricultural Biotechnology Institute (FABI), University of Pretoria, Pretoria 0002, South Africa.

Published: 13 September 2011

doi:10.1186/1753-6561-5-S7-P153

Cite this article as: Ma et al:: Development of Eucalyptus tissue culture conditions for improved in vitro plant health and transformability. BMC Proceedings 2011 5(Suppl 7):P153.
Submit your next manuscript to BioMed Central and take full advantage of:

- Convenient online submission

- Thorough peer review

- No space constraints or color figure charges

- Immediate publication on acceptance

- Inclusion in PubMed, CAS, Scopus and Google Scholar

- Research which is freely available for redistribution

Submit your manuscript at www.biomedcentral.com/submit 